\title{
Fabrication and characterization of tretinoin-loaded nanofiber for topical skin delivery
}

\author{
Saba Khoshbakht ${ }^{1}$, Farzin Asghari-Sana ${ }^{2,3}$, Anahita Fathi-Azarbayjani ${ }^{2,3^{*}}$ (D) and Yaeghob Sharifi ${ }^{4}$
}

\begin{abstract}
Background: Tretinoin or all-trans retinoic acid is used in the treatment of acne vulgaris and photo-aging. This work aims to develop tretinoin-loaded nanofibers as a potential anti-acne patch and to investigate its physicochemical characteristics.

Method: Nanofibers were produced via electrospinning method and surface topography was evaluated by Field Emission Scanning Electron Microscopy (FESEM). The functional groups of polymer and the drug molecule and the possible interactions were studied by Fourier Transform Infrared Spectroscopy (FTIR). Drug release studies were carried out by total immersion method at $25^{\circ} \mathrm{C}$ and $32{ }^{\circ} \mathrm{C}$. Tretinoin stability was evaluated at room temperature and fridge for 45 days. The possibility of synergistic antibacterial activity of tretinoin and erythromycin combination was investigated on Staphylococcus aureus (ATCC ${ }^{\circledR} 25923^{\mathrm{TM}}$ ) and $\left(\right.$ ATCC $^{\circledR} 29213^{\mathrm{TM}}$ ) by Kirby Bauer disc diffusion method.

Results: Uniform fibers without drug crystals were fabricated via electrospinning. Drug-loaded nanofibers show inherent stability under various storage conditions. Electrospun nanofibers showed a prolonged release of tretinoin. The stability of formulations in FT was higher than RT. Disc diffusion tests did not show any synergism in the antibacterial activity of erythromycin when used in combination with tretinoin.
\end{abstract}

Conclusion: It can be anticipated that the easy fabrication, low costs and dosing frequency of the construct reported here provide a platform that can be adapted for on-demand delivery of tretinoin.

Keywords: Tretinoin, Erythromycin, Nanofiber, Stability, Drug release

\section{Introduction}

Electrospinning is widely employed for the fabrication of high-quality nanofiber at low production cost. Nanofibers wound dressings can mimic extracellular matrix and minimize scar formation. Other application that can benefit from the favorable properties of nanofibers includes separation of contaminants from water and molecule filtration offered by the high efficiency and low

\footnotetext{
* Correspondence: anahita@alumni.nus.edu.sg

${ }^{2}$ Solid Tumor Research Center, Urmia University of Medical Sciences, Urmia, Iran

${ }^{3}$ Department of Pharmaceutics, School of Pharmacy, Urmia University of Medical Sciences, Urmia, Iran

Full list of author information is available at the end of the article
}

resistance structure. Various hydrophilic and hydrophobic drug molecules can be incorporated in nanofibers. The selection of a specific polymer with a known molecular weight can help in the design of a rapid, sustained or pulsatile drug delivery system $[1,2]$.

Polycaprolactone (PCL) is a biodegradable and biocompatible synthetic hydrophobic polymer with a semicrystalline structure. It has been approved by the US Food and Drug Administration (FDA) and is being widely used in the design of various drug delivery systems $[3,4]$.

Tretinoin or all-trans retinoic acid is used topically as a cream, lotion or gel for the treatment of acne. The topical application of this molecule enhances collagen

(c) The Author(s). 2020 Open Access This article is licensed under a Creative Commons Attribution 4.0 International License, which permits use, sharing, adaptation, distribution and reproduction in any medium or format, as long as you give appropriate credit to the original author(s) and the source, provide a link to the Creative Commons licence, and indicate if changes were made. The images or other third party material in this article are included in the article's Creative Commons licence, unless indicated otherwise in a credit line to the material. If material is not included in the article's Creative Commons licence and your intended use is not permitted by statutory regulation or exceeds the permitted use, you will need to obtain permission directly from the copyright holder. To view a copy of this licence, visit http://creativecommons.org/licenses/by/4.0/ The Creative Commons Public Domain Dedication waiver (http://creativecommons.org/publicdomain/zero/1.0/) applies to the data made available in this article, unless otherwise stated in a credit line to the data. 
and hyaluronic acid production and is used as an antiaging regimen. Oral administration of this drug is employed in the treatment of acute promyelocytic leukemia. However it has poor aqueous solubility, high chemical instability and it is prone to photodegradation, thermal degradation and oxidation. Tretinoin-loaded lipid-core nanocapsules have shown great enhancement in antitumoral activities as compared to the pure drug. Nanosuspensions enhance drug photostability, and chitosan solid-lipid nanoparticles improve topical delivery of tretinoin [5-9].

Tretinoin and erythromycin combination is effective in the treatment of acne. Tretinoin enhances erythromycin skin penetration and increases its efficiency and antibacterial activity by reducing cellular adhesion. This leads to drainage of excess sebum and creates an aerobic condition that may hinder the growth of anaerobic bacteria including Propionibacterium acnes [10, 11].

A combination of erythromycin and tretinoin has demonstrated enhanced efficacy in in vivo models. Thus the main purpose of this study was to develop tretinoinloaded nanofibers as a potential facial anti-acne patch and investigate its physicochemical characteristics including drug release, and stability. We also aimed to investigate the possibility of synergism in the antibacterial activity of tretinoin and erythromycin combination on Staphylococcus aureus (S. aureus) strains including (ATCC $^{\ominus} 25,923^{\text {Tw }}$ ) and $\left(\right.$ ATCC $^{\bullet} 29,213^{\text {Tw }}$ ) by Kirby Bauer disc diffusion method.

\section{Materials and methods Materials}

Tretinoin and Erythromycin were obtained from Sepidaj Pharmaceutical, Tehran, Iran. Polycaprolactone (PCL; Mw 70,000-90,000 by GPC) was purchased from SigmaAldrich. N, N-Dimethylformamide (DMF; Purity $\geq 99.0 \%$ ) was obtained from Merck (Germany). S. aureus ATCC (American Type Culture Collection 25,923 ${ }^{\mathrm{mm}}$ ) and S. aureus (ATCC $29,213^{\mathrm{mm}}$ ) were purchased from Kwik-Stik Microbiologics, France. Mueller-Hinton Agar was obtained from Becton Dickinson, France.

\section{Electrospinning of nanofibers}

A $10 \% \mathrm{w} / \mathrm{v}$ solution of polycaprolactone was prepared in dimethylformamide at $50^{\circ} \mathrm{C}$ for $4 \mathrm{~h}$. The drug was added to the polymeric solutions and placed in a syringe connected to a blunt $27 \mathrm{G}$ stainless steel needle mounted on a syringe pump (syringe pump model SP1000HOM Fanavaran Nano-Meghyas, Iran) flowing at a constant rate of $1 \mathrm{ml} / \mathrm{h}$. High voltage power supply (model HV35P OV; Fanavaran Nano-Meghyas, Iran) was applied at $19 \mathrm{kV}$ and the distance between needle and collector was $16 \mathrm{~cm}$. The electrospun nanofibers were collected on aluminum foils and dried under vacuum prior usage. Details of all formulations are shown in Table 1.

\section{Solution viscosity and Nanofiber morphology}

The viscosity of the polymeric solution was evaluated prior to electrospinning using a rotational viscometer (Evo expert viscometer; Fungilab, Spain) with a spindle L2 configuration at room temperature and a rotational speed of $200 \mathrm{rpm}$.

Fiber morphology was studied with field emission scanning electron microscopy (FESEM) (MIRA3; TESCAN, Czech Republic). Samples were sputter-coated with gold prior visualization in a high vacuum chamber at $20 \mathrm{Kv}$. Nanofiber diameter was evaluated with Image Analysis software $(n=40)$.

\section{Fourier-transform infrared spectroscopy (FTIR) analysis}

The functional groups of polymer and drug and the possible interactions between them were studied by FTIR (Spectrum Two; Perkin Elmer, USA) in the wavelength of $500-4000 \mathrm{~cm}^{-1}$ at room temperature.

\section{Drug release}

Drug release studies were performed using the total immersion method at $25^{\circ} \mathrm{C}$ and $32^{\circ} \mathrm{C}$ (this temperature was chosen to mimic the skin condition). A known amount of fiber was immersed in phosphate buffer saline, PBS ( $\mathrm{pH}$ 7.4) placed on a shaker-incubator (GFL 3031, Germany). At specific time intervals, $1 \mathrm{ml}$ samples were taken from the release medium and were replaced with the same amount of the fresh medium. Drug concentration was measured by spectrophotometer (CE7200; CECIL, United Kingdom) at the maximum wavelength of $352 \mathrm{~nm}$.

\section{Storage stability}

Tretinoin content in the nanofiber was quantified via spectrophotometer by the complete dissolution of a certain amount of fibers in a solvent. Loading dose (\%) and entrapment efficiency were calculated using the following method [12]:

$$
\text { Loading dose }(\%)=\frac{\text { Drug content }(\mathrm{mg})}{\text { Nanofiber weight }(\mathrm{mg})} \times 100
$$

Table 1 Details of the nanofiber formulations and viscosity of electrospinning solutions

\begin{tabular}{|c|c|c|c|c|}
\hline \multirow[t]{2}{*}{ Formulation } & \multicolumn{2}{|c|}{ Composition \%w/v } & \multicolumn{2}{|l|}{ Viscosity } \\
\hline & $\overline{P C L}$ & Tretinoin & Viscosity & Torque \\
\hline$A$ & 10 & 0.5 & 122.0 & $81.8 \%$ \\
\hline B & 10 & 1 & 123.1 & $82.4 \%$ \\
\hline C & 10 & - & 118.1 & $79.2 \%$ \\
\hline
\end{tabular}


Entrapment efficiency $(\%)=\frac{\text { Measured drug content }}{\text { Theoretical drug content }} \times 100$

Nanofiber stability was investigated at room temperature $\left(25^{\circ} \mathrm{C}\right)$ and fridge $\left(4-8{ }^{\circ} \mathrm{C}\right)$ for 45 days.

\section{Antimicrobial activity tests}

Disc diffusion tests were performed using S. aureus ATCC (American Type Culture Collection 25,923 ${ }^{\mathrm{Tm}}$ ) and $S\left(\right.$ ATCC $^{\ominus} 29,213^{\text {тu}}$ ) after growth in sheep blood agar at $37^{\circ} \mathrm{C}$ for $24 \mathrm{~h}$. The produced colonies were inoculated as a single colony in Mueller-Hinton Agar containing Petri dishes $(\varnothing 8 \mathrm{~cm})$ overnight at $37^{\circ} \mathrm{C}[13]$. The punched electrospun nanofiber discs $(6 \mathrm{~mm})$ were incubated at $37^{\circ} \mathrm{C}$ for $24 \mathrm{~h}$ on Muller Hinton Agar medium inoculated with bacteria suspension with turbidity adjusted to 0.5 McFarland standard. The inhibition zone was measured in millimeters $(\mathrm{mm})$ using a ruler. Three replicate were carried out under the same conditions for each sample.

\section{Statistical analysis}

All data are expressed as mean \pm SD and statistical analysis was performed by GraphPad Prism using one way ANOVA and $p<0.05$ was considered statistically significant $(n=3)$.

\section{Results}

\section{Solution viscosity and Nanofiber morphology}

The viscosity of electrospinning solutions was measured with a rotational viscometer (Table 1 ). It is seen that all formulations had similar viscosity. This may indicate that tretinoin, when used at such low concentrations did not influence solution viscosity. FESEM images of nanofiber formulations (Fig. 1) represent uniform fibers without drug crystals. The drug-loaded Fibers show gradual morphological changes with drug concentration. Formulations $\mathrm{A}$ and formulation $\mathrm{C}$ represent bead-free fibers with a diameter of $64.67 \pm 15.78 \mathrm{~nm}$ and $80.7 \pm 12.67 \mathrm{~nm}$, respectively. Formulation $B$ resulted in a mean fiber diameter of $66.81 \pm 15.68 \mathrm{~nm}$ with some beads.

\section{FTIR analysis}

The interaction between polymer and tretinoin and their functional groups were studied via FTIR (Fig. 2). In pure PCL peaks at $2864 \mathrm{~cm}^{-1}$ and $2942 \mathrm{~cm}^{-1}$ represent stretching vibrations of $\mathrm{CH}_{2}$, the peak in $1722 \mathrm{~cm}^{-1}$ attributes to stretching vibrations of $\mathrm{C}=\mathrm{O}$ and band in $1000-1300 \mathrm{~cm}^{-1}$ indicates stretching vibrations of the C-O-C group of the PCL backbone. The peak in 3438 $\mathrm{cm}^{-1}$ depicts $\mathrm{O}-\mathrm{H}$ stretching vibrations, the band in $2324 \mathrm{~cm}^{-1}$ corresponds to $\mathrm{C}=\mathrm{O}$ stretching and peaks at $960 \mathrm{~cm}^{-1}$ shows the trans vinyl $(\mathrm{CH}=\mathrm{CH})$ groups of tretinoin molecule [14-19].

\section{Drug release}

The tretinoin loading dose for formulation A and B was 4.76 and $7.94 \%$ respectively. Entrapment efficiency was found to be $99 \%$ for formulation A and $89 \%$ for formulation $\mathrm{B}$. The in-vitro drug release profile was investigated over $90 \mathrm{~h}$ in phosphate buffer solution at $32^{\circ} \mathrm{C}$ and $25^{\circ} \mathrm{C}$ (Fig. 3). In both formulations, drug release was higher at $32{ }^{\circ} \mathrm{C}$ when compared to that of $25^{\circ} \mathrm{C}(P<0.05)$. Formulation $\mathrm{A}$ and $\mathrm{B}$ released 35.65 and $37.80 \%$ of their drug content in the first $3 \mathrm{~h}$ at $25^{\circ} \mathrm{C}$ followed by a gradual drug release over the next 4 days. At $32^{\circ} \mathrm{C}, 41.21$ and $41.45 \%$ of drug content were released from formulation $\mathrm{A}$ and $\mathrm{B}$ respectively in the first $3 \mathrm{~h}$.

\section{Storage stability}

Tretinoin storage stability was studied at room temperature (RT) and fridge temperature (FT) for 45

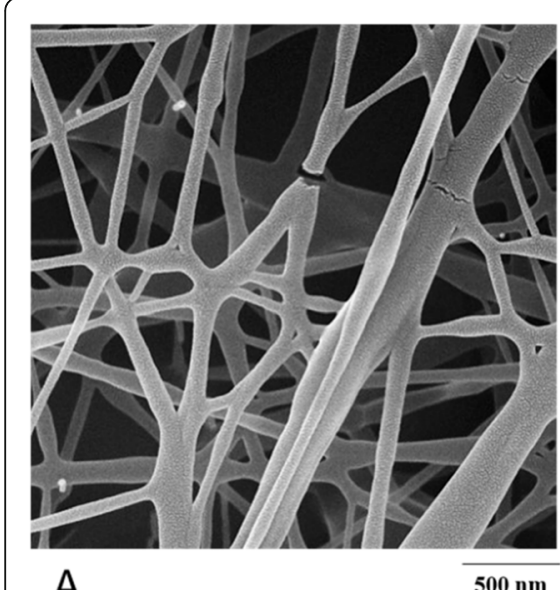

A

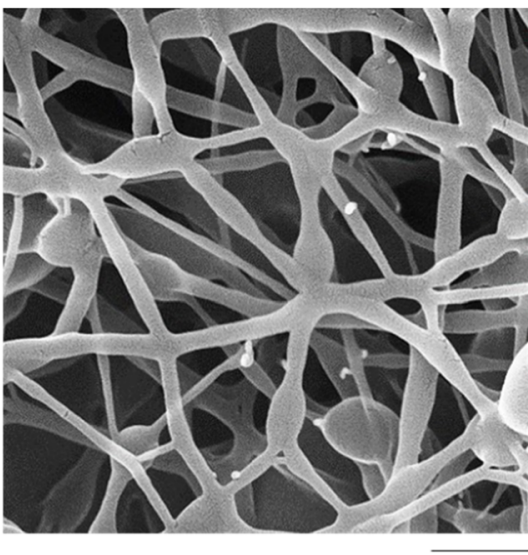

B

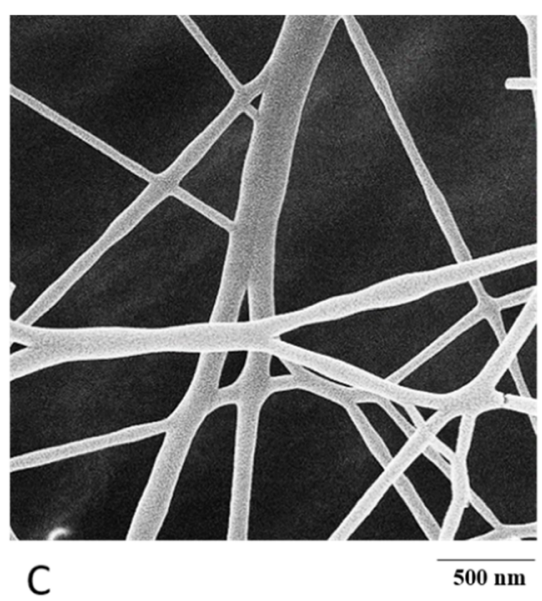

Fig. 1 FESEM images of formulations $\mathbf{a}, \mathbf{b}$ and $\mathbf{c}$ 


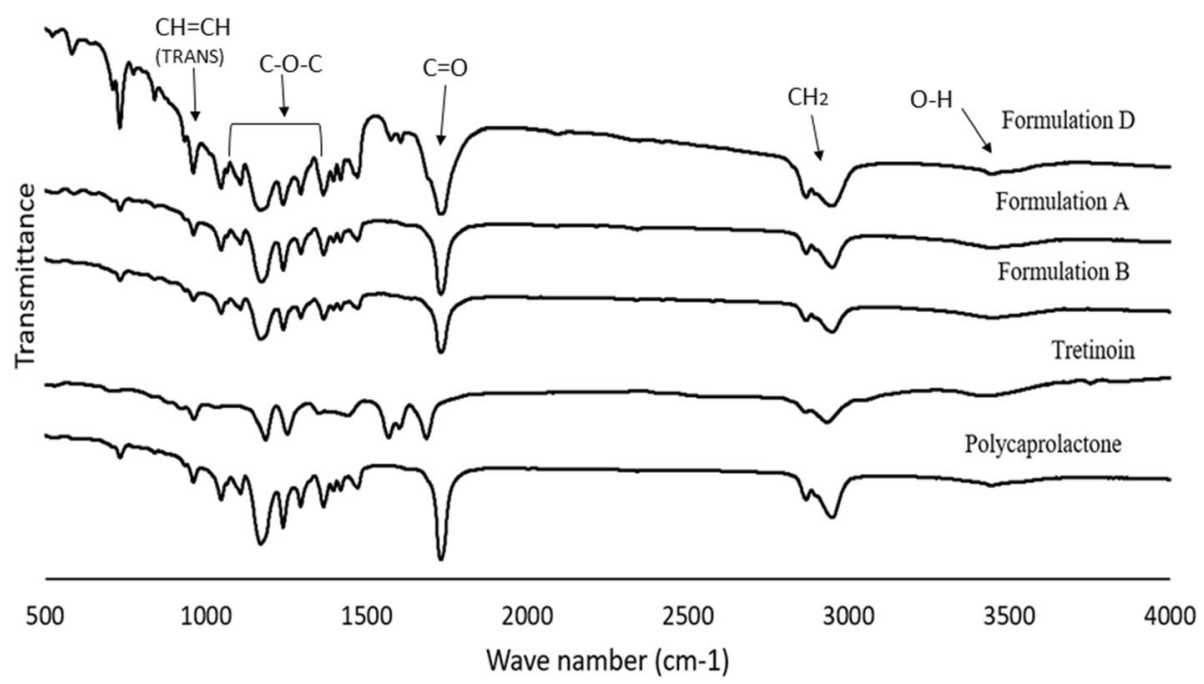

Fig. 2 FTIR spectra of various formulations

days and the results are shown in Fig. 4. At the end of 45 days, the drug content in formulations $\mathrm{A}$ and $\mathrm{B}$ was 34.7 and $30.5 \%$ respectively while storage at RT and 50.4 and $67.4 \%$ respectively at FT. Both formulations were significantly more stable in FT compared to RT after 45 days of storage $(P<0.05$ for formulation A and $P<0.001$ for formulation $\mathrm{B})$.

\section{Antimicrobial activity tests}

The possible synergism in the antibacterial activity of tretinoin and erythromycin combination was measured against S. aureus (ATCC ${ }^{\circ} 25,923^{\mathrm{mm}}$ ) and ATCC $^{\circ} 29,213^{\mathrm{mm}}$ ) by the disc diffusion method and the results are presented in Fig. 5 and Table 2. Results indicate that formulation $\mathrm{A}, \mathrm{B}$, and $\mathrm{C}$ did not display any antibacterial activity. Formulations D and E exhibited antibacterial activity against $S$. aureus (ATCC $25,923^{\mathrm{mm}}$ ) with an inhibition zones of $31 \mathrm{~mm}$. Antibacterial activity against $S$. aureus (ATCC $29,213^{\text {ma }}$ ) was similar for both formulation $\mathrm{D}$ and $\mathrm{E}$ and the inhibition zones were $32 \mathrm{~mm}$. Nanofibers showed higher inhibition diameters compared to standard erythromycin disc. This enhancement in the antibacterial effect may be attributed to the higher surface to volume ratio of nanofibers. Tretinoin did not show synergistic antibacterial effects with erythromycin.

\section{Discussion}

Tretinoin-loaded nanofibers were successfully fabricated. It was found that formulations with a higher concentration of tretinoin had some bead formation. This may be

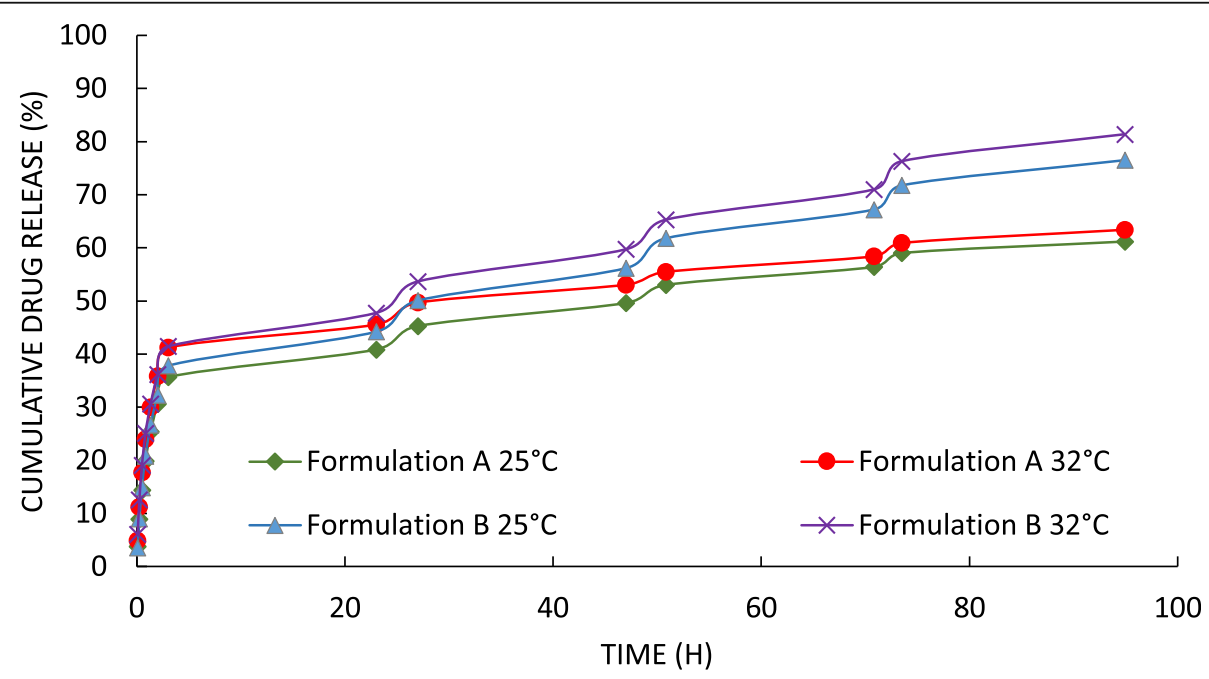

Fig. 3 Cumulative drug release profile of formulation A (Tretinoin $0.5 \% \mathrm{w} / \mathrm{v}$ ) and formulation $\mathrm{B}\left(1 \% \mathrm{w} / \mathrm{v}\right.$ ) at $25^{\circ} \mathrm{C}$ and $32^{\circ} \mathrm{C}$ 


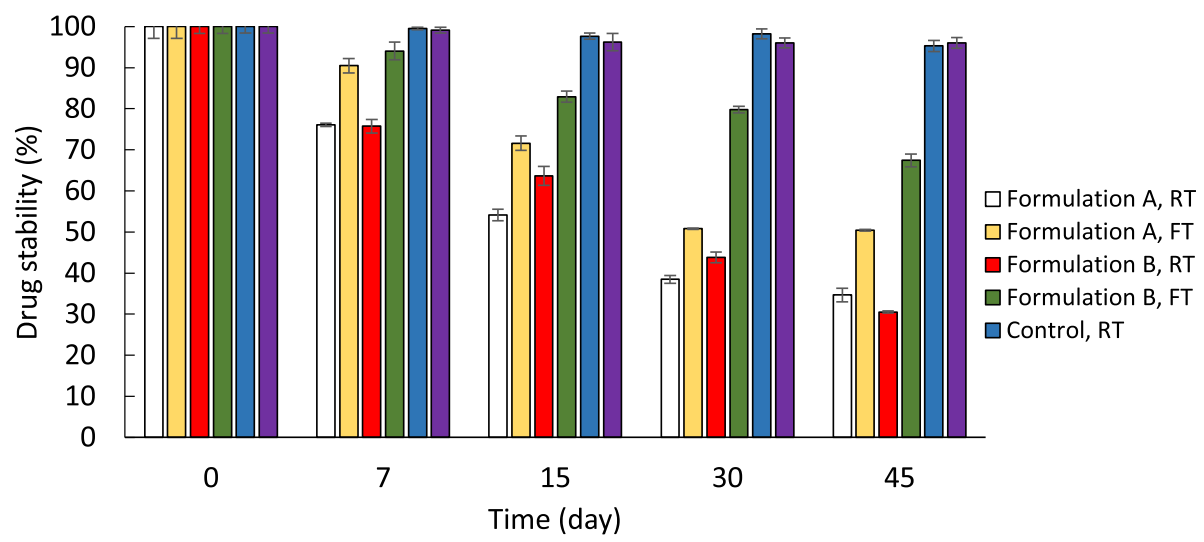

Fig. 4 Storage stability of tretinoin in (formulations A (Tretinoin $0.5 \% \mathrm{w} / \mathrm{v}$ ) and B (Tretinoin 1\% w/v). Significance difference between nanofibers stability is observed while storage at room (RT) and fridge temperature (FT). ${ }^{*} P<0.05$, ${ }^{* *} P<0.01$, *** $P<0.001$ for formulation $\mathrm{A}$ and \# $P<0.05$, $\#$ \# $P<0.01$, \#\#\# $P<0.001$ for formulation $B$

due to the higher concentration of tretinoin which may increase some of the physicochemical properties of the solution including surface tension and hydrogenic interactions between tretinoin and polymer. Due to the complete incorporation of the drug in nanofiber beds, all formulations displayed crystal-free structures [14, 15]. FTIR results indicate that all characteristic peaks are present which signify the presence of drug molecule within the polymer backbone.

Drug release from the nanofibers was carried out at two different temperatures for a period of 4 days. Both formulations showed a similar biphasic release profile and a burst release in the first $3 \mathrm{~h}$. This demonstrates the dissolution of the drug-loaded on the surface of nanofibers followed by a slow-release phase that may be due to diffusion of drug trapped inside the fibers [20]. Due to the semi-crystalline structure of PCL and its low degradation rate, part of the drug was trapped inside nanofibers which release with polymer degradation over time [21].

The chemical stability of tretinoin was tested in the developed formulations for 45 days at two different temperatures. It was found that the drug was significantly more stable in the fridge. Overall tretinoin is a vulnerable drug and is prone to instability. Results from previous studies exhibited low stability of tretinoin loaded polymeric micelles. The oxidation profile of this drug was investigated at various temperatures and it was found that tretinoin can easily oxidize even at low temperatures. Therefore decomposition by light and air should be prevented and the drug should be stored carefully to prevent oxidation. A significant decrease in drug degradation may occur when stored under an argon atmosphere, therefore a reasonable attempt should be made to decrease the degradation rate and protect from oxygen. Application of a

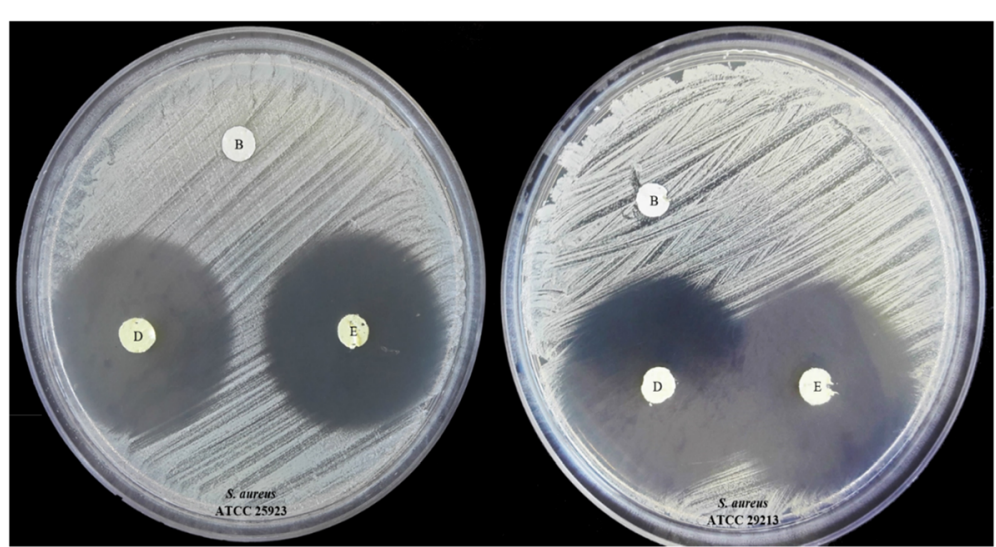

Fig. 5 In-vitro antibacterial activity of formulations B (tretinoin 1\% w/v), D (Tretinoin 1\% w/v and Erythromycin 0.7\%w/v) and $E($ Erythromycin $0.7 \% \mathrm{w} / \mathrm{v}$ ) against $\mathrm{S}$. aureus (ATCC ${ }^{\circledast} 25,923^{\mathrm{TM}}$ ) and S. aureus (ATCC ${ }^{\circledast} 29,213^{\mathrm{TM}}$ ). For formulation D and E there is no significant difference in the zone of inhibition 
Table 2 Disc diffusion test and inhibition zone diameter ( $\mathrm{mm}$ ) of electrospun nanofibers and standard antibiotic discs against S. aureus

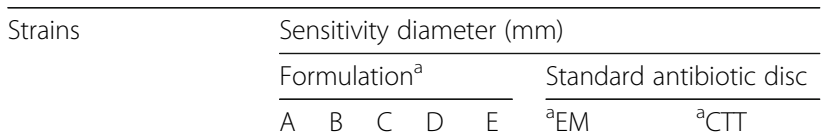

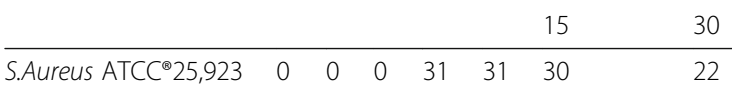

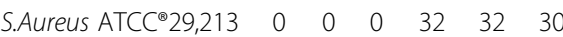

\section{3}

${ }^{\mathrm{a} A}$ : Tretinoin $0.5 \% \mathrm{w} / \mathrm{v}, \mathrm{B}$ : Tretinoin $1 \% \mathrm{w} / \mathrm{v}, \mathrm{C}$ : plain nanofiber with no drug, D: Tretinoin and Erythromycin-loaded nanofiber, E: Erythromycin-loaded nanofiber, and standard antibiotic disc including $E M$ Erythromycin and CTT Cefotetan

stabilizer is another approach that can be used to enhance drug stability [5, 22].

Previous studies have demonstrated antibacterial activity for retinaldehyde. This effect may be due to the presence of the aldehyde group which may demonstrate bifunctional property for some retinoids. Results of the disc diffusion studies on two $S$. aureus strains in this work did not exhibit any synergistic antibacterial activity in erythromycin and tretinoin combination. These results are supported by previous findings were retinoic acid and retinol did not have any antibacterial effect against gram-positive and gram-negative bacteria. Similar in vitro results were reported for tretinoin-loaded solid lipid nanoparticles with no significant antimicrobial activity against $P$. acnes (ATCC 6919) and S. aureus (ATCC 29213) $[9,23]$.

Various in vivo studies however have demonstrated that tretinoin enhances antibiotics activity of erythromycin by inhibition of trans-glutaminase activity which reduces cellular adhesion and follicular plugging and leads to drainage of excess sebum and bacteria. Tretinoin may also help create a more aerobic condition which hinders the growth of anaerobic bacteria like $P$. acnes. Application of tretinoin and clindamycin phosphate significantly improved the antibacterial and anti-inflammatory effect at various stages of acne. Recently, a combination of a topical antibiotic and tretinoin are recommended for the treatment of acne [11, 24, 25].

The results of this work demonstrate that fiber formulation can offer a great advantage for the stability of tretinoin and provide sustained release of drug at the site of action. Preliminary results obtained in this work did not indicate any synergism in tretinoin and erythromycin combination in in vitro tests; however, this formulation may help enhance its therapeutic effect in vivo.

\section{Conclusion}

The overall purpose of the study was to fabricate nanofibers containing tretinoin as a drug delivery system for the treatment of acne. Uniform fibers without drug crystals were fabricated via electrospinning. Formulations were investigated for drug release, stability and antimicrobial activity in combination with erythromycin. Electrospun nanofibers showed a prolonged release of tretinoin. The stability of formulations in FT was higher than RT. It can be anticipated that the easy fabrication, low costs and dosing frequency of the construct reported here provide a platform that can be adapted for on-demand delivery of tretinoin, either solo or in combination with erythromycin. Formulation changes and the addition of other pharmaceutical excipients for improving drug stability and release will be explored in future research.

\section{Abbreviations}

FESEM: Field emission scanning electron microscopy; FT: Fridge temperature; FTIR: Fourier-transform infrared spectroscopy; P. acnes: Propionibacterium acnes; PCL: Poly caprolactone; RT: Room temperature; $S$.

aureus: Staphylococcus aureus

\section{Acknowledgments}

Not applicable.

\section{Authors' contributions}

SK contributes to data handling and experimental analysis. FAS contributed to experimental analysis and antimicrobial tests. AFA contributed to data analysis, study design, supervision, and draft preparation. YS performed antimicrobial tests. The authors read and approved the final manuscript.

\section{Funding}

The authors would like to thank Urmia University of Medical Sciences for providing financial (Grant No. 1395-2098) support for carrying out this project.

\section{Availability of data and materials}

Data associated with this paper is available from the corresponding author upon reasonable request.

\section{Ethics approval and consent to participate}

Not applicable.

\section{Consent for publication}

Not applicable.

\section{Competing interests}

The authors declare that they have no competing interests.

\section{Author details}

${ }^{1}$ Student Research Committee, Urmia University of Medical Science, Urmia, Iran. ${ }^{2}$ Solid Tumor Research Center, Urmia University of Medical Sciences, Urmia, Iran. ${ }^{3}$ Department of Pharmaceutics, School of Pharmacy, Urmia University of Medical Sciences, Urmia, Iran. ${ }^{4}$ Department of Clinical Microbiology, School of Medicine, Urmia University of Medical Sciences, Urmia, Iran.

Received: 3 December 2019 Accepted: 21 February 2020

Published online: 02 March 2020

References

1. Leung WWF, Hau CWY, Choy HF. Microfiber-nanofiber composite filter for high-efficiency and low pressure drop under nano-aerosol loading. Sep Purif Technol. 2018;206:26-38.

2. Fathi-Azarbayjani A, Khu JV, Chan YW, Chan SY. Development and characterization of skin permeation retardants and enhancers: a comparative study of levothyroxine-loaded PNIPAM, PLA, PLGA and EC microparticles. Biopharm Drug Dispos. 2011;32:380-8.

3. Goyal R, Macri LK, Kaplan HM, Kohn J. Nanoparticles and nanofibers for topical drug delivery. J Control Release. 2016;240:77-92.

4. Ning W, Shang P, Wu J, Shi X, Liu S. Novel amphiphilic, biodegradable, biocompatible, thermo-responsive ABA triblock copolymers based on PCL and PEG analogues via a combination of ROP and RAFT: synthesis, 
characterization, and sustained drug release from self-assembled micelles. Polymers. 2018;10(2):214.

5. Teraoka R, Konishi Y, Matsuda Y. Photochemical and oxidative degradation of the solid-state tretinoin tocoferil. Chem Pharm Bull. 2001;49(4):368-72.

6. Fachinetto JM, Ourique AF, Tedesco SB, Silva AC, Beck RCR. Tretinoin-loaded polymeric nanocapsules: evaluation of the potential toimprove the antiproliferative activities on Allium cepa root-tip compared to the free drug. Lat Am J Pharm. 2008;27(5):668-73.

7. Schultze E, Ourique A, Yurgel VC, Begnini KR, Thurow H, de Leon PMM, Campos VF, Dellagostin OA, Guterres SR, Pohlmann AR, Seixas FK. Encapsulation in lipid-core nanocapsules overcomes lung cancer cell resistance to tretinoin. Eur J Pharm Biopharm. 2014;87(1):55-63.

8. Lai F, Pireddu R, Corrias F, Fadda AM, Valenti D, Pini E, Sinico C Nanosuspension improves tretinoin photostability and delivery to the skin. Int J Pharm. 2013:458(1):104-9.

9. Ridolfi DM, Marcato PD, Justo GZ, Cordi L, Machado D, Durán N. Chitosansolid lipid nanoparticles as carriers for topical delivery of tretinoin. Colloids Surf B: Biointerfaces. 2012;93:36-40.

10. Tan HH. Topical antibacterial treatments for acne vulgaris. Am J Clin Dermatol. 2004;5(2):79-84.

11. Schmidt N, Gans EH. Tretinoin: a review of its anti-inflammatory properties in the treatment of acne. J Clin Aesthet Dermatol. 2011:4(11):22-9.

12. Tonglairoum P, Ngawhirunpat T, Rojanarata T, Kaomongkolgit R, Opanasopit P. Fabrication of a novel scaffold of clotrimazole-microemulsion-containing nanofibers using an electrospinning process for oral candidiasis applications. Colloids Surf B: Biointerfaces. 2015:126:18-25.

13. CLSI, C. 2012. Performance standards for antimicrobial susceptibility testing. Clinical and laboratory standards institute (M100eS22).

14. Canbolat MF, Celebioglu A, Uyar T. Drug delivery system based on cyclodextrin-naproxen inclusion complex incorporated in electrospun polycaprolactone nanofibers. Colloids Surf B: Biointerfaces. 2014;115:15-21.

15. Pillay V, Dott C, Choonara YE, Tyagi C, Tomar L, Kumar P, du Toit LC, Ndesendo VM. A review of the effect of processing variables on the fabrication of electrospun nanofibers for drug delivery applications. J Nanomater. 2013;789289:22.

16. Ghate VM, Lewis SA, Prabhu P, Dubey A, Patel N. Nanostructured lipid carriers for the topical delivery of tretinoin. Eur J Pharm Biopharm. 2016;108:253-61.

17. Liu M, Luo G, Wang Y, He W, Liu T, Zhou D, Hu X, Xing M, Wu J. Optimization and integration of nanosilver on polycaprolactone nanofibrous mesh for bacterial inhibition and wound healing in vitro and in vivo. Int J Nanomedicine. 2017;12:6827-40.

18. Natarajan V, Krithica N, Madhan B, Sehgal PK. Formulation and evaluation of quercetin polycaprolactone microspheres for the treatment of rheumatoid arthritis. J Pharm Sci. 2011;100(1):195-205.

19. Salem IB, Mezni M, Boulila A, Hamdi M, Saidi M. Removal of penicillin G and erythromycin with ionizing radiation followed by biological treatment. Curr Microbiol. 2016;73(4):582-6.

20. Samprasit W, Rojanarata T, Akkaramongkolporn P, Ngawhirunpat T, Kaomongkolgit R, Opanasopit P. Fabrication and in vitro/in vivo performance of mucoadhesive electrospun nanofiber mats containing amangostin. AAPS PharmSciTech. 2015;16(5):1140-52.

21. Hall Barrientos IJ, Paladino E, Szabó P, Brozio S, Hall PJ, Oseghale Cl, Passarelli MK, Moug SJ, Black RA, Wilson CG, Zelkó R, Lamprou DA. Electrospun collagenbased nanofibres: a sustainable material for improved antibiotic utilisation in tissue engineering applications. Int J Pharm. 2017;531(1):67-79.

22. Lapteva M, Möller M, Gurny R, Kalia YN. Self-assembled polymeric nanocarriers for the targeted delivery of retinoic acid to the hair follicle. Nanoscale. 2015;7(44):18651-62.

23. Pechere M, Germanier L, Siegenthaler G, Pechère JC, Saurat JH. The antibacterial activity of topical retinoids: the case of retinaldehyde. Dermatology. 2002;205(2):153-8.

24. Lee WS, Park YS, Cho YK. Significantly enhanced antibacterial activity of TiO 2 nanofibers with hierarchical nanostructures and controlled crystallinity. Analyst. 2015;140(2):616-22.

25. Leyden JJ. In vivo antibacterial effects of tretinoin-clindamycin and clindamycin alone on Propionibacterium acnes with varying clindamycin minimum inhibitory. J Drugs Dermatol. 2012;11(12):1434-8.

\section{Publisher's Note}

Springer Nature remains neutral with regard to jurisdictional claims in published maps and institutional affiliations.

\section{Ready to submit your research? Choose BMC and benefit from:}

- fast, convenient online submission

- thorough peer review by experienced researchers in your field

- rapid publication on acceptance

- support for research data, including large and complex data types

- gold Open Access which fosters wider collaboration and increased citations

- maximum visibility for your research: over $100 \mathrm{M}$ website views per year

At BMC, research is always in progress.

Learn more biomedcentral.com/submissions 